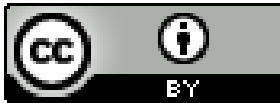

\title{
W. E. B. DU BOIS NO CENTRO: DA CIÊNCIA, DO MOVIMENTO DE DIREITOS CIVIS, AO MOVIMENTO BLACK LIVES MATTER
}

\author{
Título original - W. E. B. Du Bois at the center: from science, civil rights movement, \\ to Black Lives Matter) MORRIS, Aldon, British Journal of Sociology 68 (1)2017, pp. \\ 3-16.
}

\section{Coordenação da Tradução: Valter Roberto Silvério ${ }^{1}$ Tradução: Hasani Elioterio dos Santos ${ }^{2}$ Tradução: Fernando Oliveira da Costa ${ }^{3}$ Revisão: Carolina Nascimento de Melo ${ }^{4}$}

Resumo: É uma honra apresentar a palestra anual na Escola de Economia de Londres ${ }^{5}$ ao Jornal Britânico de Sociologia em 2016. Minha palestra é baseada nas ideias derivadas do meu novo

\footnotetext{
${ }^{1}$ Professor Titular do Departamento e Programa de Pós-graduação em Sociologia da Universidade Federal de São Carlos (UFSCar) e pesquisador CNPq. Vice-presidente do International Scientific Committee for Volume IX, X and XI of the General History of Africa - GHA - UNESCO.
2 Doutorando do Programa de Pós-Graduação em Sociologia da Universidade Federal de São Carlos, membro o grupo de pesquisa Estudos da Diáspora e do Núcleo de Estudos Afro-brasileiros (NEAB - UFSCar).

${ }^{3}$ Mestrando do Programa de Pós-Graduação em Sociologia da Universidade Federal de São Carlos e membro do grupo de pesquisa Estudos da Diáspora.

\begin{abstract}
${ }^{4}$ Mestranda no Programa de Pós-Graduação em Sociologia da Universidade Federal de São Carlos. Bolsista pela Coordenação de Aperfeiçoamento de Pessoal de Nível Superior (Capes) e membro do grupo de pesquisa Estudos da Diáspora vinculado ao Núcleo de Estudos Afro-Brasileiros da Universidade Federal de São Carlos (NEAB/UFSCar).
\end{abstract}

${ }^{5} \mathrm{O}$ British Journal of Sociology é um importante jornal internacional de sociologia publicado em nome da London School of Economics and Political Science (LSE). Com foco nas questões sociológicas sociais e democráticas de nosso tempo, esta renomada revista lidera o debate sobre questões metodológicas e teóricas importantes e controvérsias na sociologia contemporânea. O coordenador da tradução, e equipe, agradecem à licença concedida para a tradução por John Wiley \& Sons Limited, em 8 de abril de 2020 sob o n $^{\circ} 35508$ (PLSclear). E, também, ao Professor Aldon Morris e ao editor chefe do British Journal of Sociology Professor Nigel Dodd pelos esforços para que a tradução fosse possível. Foram incluídas notas de rodapé adicionais sempre que consideramos necessárias para facilitar o entendimento do texto. In: https://onlinelibrary.wiley.com/page/journal/14684446/homepage/productinformation.html Pesquisado em 12/04/2020. 
livro The Scholar Denied: W.E.B. Du Bois and the Birth of Modern Sociology (2015). Neste ensaio eu desenvolvo três argumentações. Primeiro, W.E.B. Du Bois e sua Escola de Sociologia em Atlanta foram os pioneiros da sociologia científica nos Estados Unidos. Segundo, Du Bois foi o pioneiro de uma sociologia pública que combinou criativamente sociologia e ativismo. E, finalmente, Du Bois foi o pioneiro de uma ciência social engajada relevante às lutas políticas contemporâneas incluindo o movimento contemporâneo Black Lives Matter ${ }^{6}$.

Palavras-chave: W.E.B Du Bois; Escola de Atlanta; sociologia científica; teoria sociológica; discriminação sociológica e marginalização

\title{
W. E. B. DU BOIS AT THE CENTER: FROM SCIENCE, CIVIL RIGHTS MOVEMENT, TO BLACK LIVES MATTER
}

\begin{abstract}
I am honoured to present the 2016 British Journal of Sociology Annual Lecture at the London School of Economics. My lecture is based on ideas derived from my new book, The Scholar Denied: W.E.B. Du Bois and the Birth of Modern Sociology. In this essay I make three arguments. First, W.E.B. Du Bois and his Atlanta School of Sociology pioneered scientific sociology in the United States. Second, Du Bois pioneered a public sociology that creatively combined sociology and activism. Finally, Du Bois pioneered a politically engaged social science relevant for contemporary political struggles including the contemporary Black Lives Matter movement.
\end{abstract}

Keywords: W. E. B. Du Bois; Atlanta School; scientific sociology; sociological theory; sociological discrimination and marginalization

\section{CIÊNCIA INOVADORA DA SOCIEDADE}

Há um intrigante segredo bem escondido envolvendo a fundação da sociologia cientifica na América. A primeira escola americana de sociologia científica foi fundada por um professor negro, localizado em uma universidade negra pequena, economicamente pobre e racialmente segregada. No lumiar do século XIX - de 1898 a 1910 - o sociólogo e ativista, W. E. B Du Bois, desenvolveu a primeira escola cientifica de sociologia na histórica Universidade de Atlanta ${ }^{7}$.

\footnotetext{
${ }^{6}$ Tanto o termo I can't breathe (eu não consigo respirar) como o termo Black lives matter (vidas negras importam) marcam o ativismo afro-americano, mas também transnacional no século XXI após os casos de violência policial cometida contra jovens negros. O Black lives matter teve início em 2013 após a absolvição do policial George Zimmerman no assassinato do jovem Trayvon Martin, já o termo I can 't breathe advém de Eric Garner, vítima de violência policial e morto por asfixia no dia 17 de julho 2014 pelo policial Daniel Pantaleo em Nova York. Os casos tiveram origem nos EUA, mas tiveram adesão global, se caracterizando em uma mobilização transnacional contra a violência policial e o genocídio dos jovens negros.
}

${ }^{7}$ A Clark Atlanta University foi formada com a consolidação da Atlanta University e do Clark College, ambas com posições únicas nos anais da história afro-americana. A Universidade de Atlanta, criada em 1865 pela American Missionary Association, foi a primeira instituição do país a conceder diplomas de graduação a afro-americanos. O Clark College, fundada quatro anos depois em 1869, foi a primeira 
É uma afirmação monumental argumentar que Du Bois desenvolveu a primeira escola científica de sociologia na América. De fato, meu propósito em escrever The Scholar Denied (2015) era deslocar nosso entendimento sobre os pais fundadores das ciências sociais nos EUA, depois de mais de cem anos atrás. As histórias existentes da origem (Bernard; Bernard, 1943; Turner; Turner, 1990; Madge, 1962) consideram apenas os acadêmicos homens e brancos, de prestigio nas universidades brancas, como sendo os arquitetos da sociologia científica americana. Nesta abordagem, os cientistas sociais negros, assim como as universidades negras, não são sequer identificados como colaboradores marginais do desenvolvimento da sociologia científica. Deste modo, pretendo demonstrar que estas narrativas são imprecisas, pois falham em reconhecer, ou mesmo mencionar, o papel fundamental do pioneirismo que Du Bois desempenhou na sociologia científica da Escola de Atlanta.

Ainda no livro The Scholar Denied, eu argumento que se as ideias e metodologias inovadoras de Du Bois tivessem sido colocadas no centro das abordagens intelectuais pioneiras da sociologia um século atrás, elas teriam fornecido direções teóricas e metodológicas poderosas para esta nova ciência social. Neste sentido, a negação acadêmica do pensamento de Du Bois empobreceu a sociologia desde suas origens. Assim, o livro The Scholar Denied (2015) visa mudar nosso entendimento sobre uma parte da história social americana. Ao fazê-lo, meu objetivo é desafiar os paradigmas existentes, rompendo com as narrativas dominantes, dando luz a novas verdades.

Hoje, nós assumimos as ciências sociais como campos de investigação existentes há muito tempo. Mas, no tempo histórico eles são recentes. Eles emergiram nas últimas décadas do século dezenove. O primeiro departamento de sociologia foi fundado na Universidade de Chicago em $1892^{8}$. Três anos depois, os sociólogos de Chicago fundaram o American Journal of Sociology ${ }^{9}$, a primeira revista científica periódica no campo da

\footnotetext{
faculdade de artes liberais do país a servir uma população estudantil principalmente afro-americana. https://www.cau.edu/about/index.html Acesso em 12/04/2020

${ }^{8}$ A fundação do Departamento de Sociologia coincide com a fundação da Universidade de Chicago em 1892. Já o termo "Escola de Chicago" é o nome dado ao grupo de professores e pesquisadores da Universidade de Chicago que emergiu durante os anos 20 e que trouxeram contribuições significantes para a área da sociologia. Destacam-se alguns nomes como Robert E. Park, Florian Znaniecki, William I. Thomas e Howard Becker. Dentre os temas explorados pela Escola de Chicago destacamos os trabalhos sobre crime, urbanização, relações raciais, desenvolvimento industrial e migração.
}

${ }^{9}$ O American Journal of Sociology é um periódico acadêmico bimensal fundado em 1895 e é o primeiro periódico da sociologia enquanto disciplina. 
sociologia. Em 1905, foi organizada a primeira associação nacional de sociologia - a American Sociological Society. A sociologia americana, portanto, é um produto do fim do século XIX e início das primeiras décadas do século XX.

Entretanto, quando a nascente sociologia americana é examinada de maneira cuidadosa, fica claro que ela não é tão científica. A primeira geração de sociólogos americanos coletou poucos dados empíricos para fundamentar seus tratados sociológicos. (Small, 1916). Quando pensamos em sociologia nos dias de hoje temos em mente estudos onde surveys ${ }^{10}$ são desenvolvidos, entrevistas conduzidas, trabalhos de campo empreendidos e os dados quantitativos e qualitativos utilizados para documentar e interpretar as condições humanas. O propósito destas metodologias empíricas consiste em fornecer evidências que possibilitem aos sociólogos testarem suas hipóteses e encontrar conclusões científicas válidas.

Desta forma, os sociólogos contemporâneos não podem simplesmente afirmar "meus estudos são validos porque temos título de doutorado de uma instituição de elite", ou que "minhas opiniões são precisas porque estão baseadas em minhas reflexões profundas". Na sociologia contemporânea, presume-se que acadêmicos testem teorias com dados empíricos e façam com que estes dados estejam à disposição para que outros pesquisadores possam testá-los e chegar a julgamentos independentes a respeito da validade cientifica dos argumentos postos.

Não obstante este enfoque de base empírica era raro no início da formação da sociologia americana. A maior parte da sociologia daquele período foi essencialmente mais uma filosofia social do que uma sociologia cientifica, porque confiava na "teorização de gabinete" ${ }^{11}$, ou que Du Bois se referiu como sendo uma sociologia feita da "janela do carro“, querendo dizer que tal concepção de estudo social não era rigorosa (Du Bois, 1903). Uma sociologia de janela de carro não é uma ciência rigorosa porque é baseada em palpites, rumores, filmes de viagens e opiniões formadas de modo vago.

\footnotetext{
${ }^{10}$ A pesquisa survey é um modelo de pesquisa quantitativa, com o objetivo de coletar dados e informações a partir de opiniões e relatos de grupos de pessoas que participem respondendo, em geral, um questionário ou formulário que contenham perguntas já estruturadas em torno de algumas categorias analíticas.

${ }^{11}$ Trata-se do que popularmente se chama de "sociologia de gabinete", baseada em especulações, conjecturas e quando muito em observações casuais de determinados fatos inscritos aos problemas de pesquisa.
} 
A sociologia americana no início tinha uma outra componente durável: era racista. Quando a sociologia começou a tomar forma, na virada do século $\mathrm{XX}$, o racismo americano estava no auge. O racismo do Jim $\mathrm{Crow}^{12}$ foi substituído por um racismo mais liberal do período da Reconstrução ${ }^{13}$. A era Jim Crow inaugurou no sistema de dívida de peonagem ${ }^{14} \mathrm{e}$ de arrendamento uma relação que substituiu o trabalho escravo. Os linchamentos em que negros foram enforcados em árvores eram corriqueiros, como os que a cantora de Jazz, Billie Holiday ${ }^{15}$, a cantar tristemente, "Árvores do sul carregam uma fruta estranha, sangue nas folhas e sangue na raiz, corpos negros balançando na brisa do sul, estranhas frutas penduradas nos tronco das árvores." Seguindo a Reconstrução a população negra foi proibida de votar, explorada economicamente e tratada como sub-humanos, sem nenhum direito que os brancos fossem obrigados a respeitar. Como durante a escravidão americana, as condições pós-reconstrução levaram os ex-escravizados a cantarem: "Ninguém sabe os problemas que eu tenho vivido".

\footnotetext{
${ }^{12}$ O período do Jim Crow é caracterizado pelo decreto de Leis estaduais que tinham o objetivo de impor a segregação racial nos Estados Unidos. As leis foram promulgadas em um período que compreende o final do século XIX e início do século XX e tiveram aplicação até 1965. Em 1896 a Suprema Corte aprovou no caso Plessy v. Ferguson, a formalização do Jim Crow no Sul dos Estados Unidos, em uma votação de 7 votos a 1. O caso se popularizou por ter concedido constitucionalidade aos estados da União de exercer a segregação formal e institucional com o viés racial em qualquer local público, sob a alegação de que os cidadãos eram "separados, mas iguais". Este caso foi paradigmático, pois explicitou para o mundo todo o que alguns autores como Harry E. Groves (1951) apontam ser a doutrina jurídica dos Estados Unidos que embasou e fundamentou a segregação racial dos EUA no século XX. In: GROVES, H. E. Separate but Equal. The Doctrine of Plessy v. Ferguson. In: Phylon (1940-1956), v. 12, n. 1, p. 66-72, 1951.
}

\footnotetext{
${ }^{13}$ O período da Reconstrução dos Estados unidos inicia com o fim da Guerra Civil em 1896 e dura até 1877. Esse contexto é marcado por alguns feitos práticos que foram realizados a nível de Estado como a institucionalização do Freeman's Bureau, $a$ aprovação da $14^{\mathrm{a}}$ e a $15^{\mathrm{a}}$ Emendas constitucionais, que foram motivadas, em certa medida, por um desejo em assegurar direitos aos afro-americanos recém libertos . No entanto o período da Reconstrução também é marcado pela insurgência da supremacia branca. Segundo Loewen (1995) entre 1865 e 1867 durante o governo do Partido Democrata dos EUA um negro era assassinado por dia em Hinds County, no Mississippi, as escolas negras eram os alvos principais de incêndios, professores eram açoitados, violentados e ocasionalmente mortos. In: LOEWEN, J. W. Lies My Teacher Told Me: Everything Your American History Textbook Got Wrong. Nova Iorque: Simon \& Schuster, 1995.

${ }^{14}$ Trata-se de uma relação de servidão, escravidão por meio de dívidas.

${ }^{15}$ Billie Holiday (1915-1959) nasceu na Filadélfia, Pensilvânia, foi uma estrela do seu tempo. Ela ganhou destaque nos anos 1930 com um estilo único que reinventou as convenções do canto e performance modernos. Nos anos 1930, durante sua passagem épica no Cafe Society de Barney Josephson, em Manhattan, ela foi apresentada ao poema "Strange Fruit", uma horrível representação de linchamento no sul dos Estados Unidos. A música foi escrita apenas para Billie e se tornou a marca registrada de seus shows. É considerada pelos estudiosos a primeira música de protesto da era dos direitos civis. A letra era tão controversa que sua gravadora não gravaria. Então ela pulou para a Commodore Records independente, onde poderia gravar e cantar como quisesse. "Strange Fruit" imediatamente se tornou um ponto de ignição cultural e um recorde de sucesso também. Acessado em 12/04/20 cf https://billieholiday.com/bio/
} 
Este racismo pernicioso apresentava a América com desafios fundamentais: como podia uma autoconsagrada democracia que declara "Dá-me suas massas cansadas, pobres e encolhidas desejosas de respirar livremente", justificar a opressão de milhares do povo negro? Como poderia a América se justificar a si própria e ao mundo, que a opressão racial e a democracia eram congruentes? A América branca endereçou esse paradoxo, transferindo a ideologia da supremacia branca manufaturada durante a escravidão para $o$ regime Jim Crow. Essa ideologia mantinha os negros enquanto uma raça inferior mais parecida com os chimpanzés do que seres humanos. Insistia que negros eram subhumanos infestados com DNA inferior e uma cultura defeituosa. Os negros foram enquadrados como prisioneiros da inferioridade racial e definhavam no limbo da sociedade e iriam para sempre permanecer lá, porque Deus planejou desta forma.

Enraizada em ideias popularizadas durante o iluminismo, a ciência do início do século XX estava ganhando força como sendo um modo superior de raciocínio. Mas essa ciência suscitou uma pergunta espinhosa: era possível que uma ciência rigorosa da raça pudesse produzir evidências desacreditando a ideologia da inferioridade negra?

Em outras palavras, a teoria da supremacia branca era consistente com os fatos científicos? No entanto, esse embate entre ideologia e ciência não se materializou. Estudiosos brancos em todos os campos da academia, das ciências às humanidades, da biologia à literatura e da história à sociologia chegaram a um sólido consenso argumentando que a ciência realmente provou que os negros eram inferiores. Assim, no início do século XX, a ciência branca e a ideologia da supremacia branca caminhavam de mãos dadas justificando a opressão racial (McKee, 1993). No entanto, um desafio às certezas desta ciência racista em breve, seria lançado.

Na última década do século XIX, W.E.B. Du Bois tornou-se um jovem confiante, brilhante e convencido de sua própria genialidade (Lewis, 1993). Du Bois também estava convencido de que Deus não havia feito os negros inferiores. Em uma época em que os brancos viam os negros como inferiores, as próprias conquistas de Du Bois eram surpreendentemente inconsistentes com o mito da inferioridade negra. Aos 20 anos, Du Bois se formou na Universidade de Fisk ${ }^{16}$; aos 22 anos, ele obteve seu segundo

\footnotetext{
${ }^{16}$ A Fisk University é uma instituição de ensino superior fundada em 1866 Nashville, Tennessee, ela é caracterizada por ser uma importante universidade negra norte-americana.
} 
bacharelado da Universidade de Harvard ${ }^{17}$; aos 23 anos, ele obteve o título de mestrado por Harvard; aos 25 anos, Du Bois completou dois anos de estudos avançados de pósgraduação na Universidade de Berlim. E com 27 anos Du Bois tornou-se o primeiro afroamericano a obter um $\mathrm{PhD}$ na Universidade de Harvard. Sua tese de doutorado, The Suppression of the African Slave-Trade to the United States of America, 1638-1870, tornou-se o primeiro volume publicado no periódico de Harvard "Série de Estudos Históricos" de 1896 (Du Bois, 1896) ${ }^{18}$.

Deste modo, Du Bois foi uma das pessoas mais educadas do mundo durante o período em que negros eram vistos como inferiores. De fato, sua genialidade, e educação avançada, assim como sua auto-confiança, o preparou para se tornar um acadêmico de renome que estaria pronto para lançar um ataque para derrubar a ideologia de que Deus teria criado os negros como inferiores. Essa ideologia, segundo Du Bois, seria derrubada se os negros se libertassem da opressão racial. Mas Du Bois enfrentou um grande desafio intelectual: Como ele iria engendrar a superação do racismo científico?

A preparação acadêmica de Du Bois forneceu a ele uma base sólida para iniciar o ataque. Através de seus subsídios para os estudos históricos e sociológicos, Du Bois descobriu fragilidades intelectuais profundas nas ciências sociais. Ele sabia que o conhecimento sociológico do período se baseava em preconceitos raciais enraizados de maneira profunda nas almas dos acadêmicos brancos. Du Bois, insistindo em uma concepção crítica de ciência social escreveu:

Infelizmente [...] é o fato que grande parte do trabalho feito sobre a questão dos negros é notoriamente acrítico; acrítica por falta de discriminação na seleção e ponderação de evidências, acrítica na escolha do ponto de vista adequado para estudar esses problemas e, por fim, acrítica em relação ao viés distinto provindo da mente de tantos escritores (DU BOIS, 1898).

Du Bois reconheceu que esses estudos tendenciosos sobre a população negra não foram contestados por estudiosos brancos, porque eram consistentes com a ideia de supremacia apoiada pelas elites brancas. Ele sabia que a ciência existente da "raça" não se baseava em fatos empíricos, mas em especulação e conjectura. Du Bois também sabia que as teorias sociológicas de "raça" emergiram plenamente da mente de estudiosos

\footnotetext{
17 A Harvard University foi fundada em 1636 e é uma instituição de ensino superior de prestígio, membro da Ivy League, um grupo composto pelas oito universidades mais ricas e com prestígio dos Estados Unidos.

18 “A supressão do tráfico de escravos africanos para os Estados Unidos da América, 1638-1870".
} 
brancos que nunca saíram de seus escritórios ou bibliotecas para realizar pesquisas (Du Bois, 1904).

Assim, o grande desafio de Du Bois foi desenvolver uma nova sociologia científica que descobrisse as causas reais da opressão racial. Em retrospecto, era ambicioso o desejo de Du Bois de construir uma nova sociologia. Ao longo da história, poucos estudiosos desenvolveram novos paradigmas científicos. No entanto, esse estudioso negro, preso dentro dos limites do confinamento de um intenso racismo, decidiu por desacreditar o discurso racista mascarado como ciência. A missão de Du Bois era clara: ele pretendia inserir a ciência na sociologia conduzindo estudos concretos entre pessoas reais - seu povo - um povo que vivia e morria atrás do véu do racismo ${ }^{19}$.

Inicialmente, Du Bois supôs que os brancos oprimiam os negros porque eram vítimas da ignorância e que realmente acreditavam no mito da superioridade branca. Du Bois argumentou que uma sociologia científica demonstraria que o preconceito racial e discriminação causava o problema ao invés do "DNA preto". Ele declarou que: "O mundo estava errado sobre raça, porque a desconhecia. O mal extremo era a estupidez" (Du Bois, 1940). Du Bois acreditava que uma sociologia científica poderia libertar os brancos do seu pensamento racista e capacitar os negros, porque "o problema estava em minha mente e era uma questão de investigação sistemática e de uma compreensão inteligente”. Assim, Du Bois prometeu fazer o mundo pensar direito sobre a "raça", desenvolvendo uma ciência social de base científica. Ao fazer isso, ele se separou dos seus colegas sociólogos brancos que produziram uma sociologia não científica.

Du Bois estava ciente dos erros científicos cometidos pelos cientistas sociais brancos. Primeiro, seus raciocínios não eram informados pela história; segundo, eles não faziam uso de dados quantitativos para medir cuidadosamente os fenômenos sociais; terceiro, eles falharam em conhecer intimamente as populações, situando-se entre pessoas reais onde eles poderiam observar suas vidas diárias; quarto, eles não conseguiram entrevistar pessoas para apreender sobre suas realidades; quinto, eles não realizaram estudos empíricos sobre as populações analisadas; e sexto, e pior de todos: eles substituíram as verdades sociológicas por crenças racistas. Para Du Bois, essa marca de pseudoconhecimento não merecia o nome "ciência".

\footnotetext{
${ }^{19}$ A noção de véu em Du Bois opera como uma metáfora que simboliza um processo semelhante à ideia de racialização em Franz Fanon, remetendo à ideia de particularizar dois universos diferentes, o universo branco e o não-branco, ou segundo a noção de véu em Du Bois, a ideia de dentro e fora do véu.
} 
Em nítido contraste, a sociologia de Du Bois fazia uso de um método científico rigoroso. Tendo obtido seu doutorado em Harvard, na área da história, Du Bois sempre ancorou sua sociologia na história, argumentando que não há como entender as pessoas se não situá-las em um contexto histórico apropriado. Na Universidade de Berlim, Du Bois adquiriu domínio dos métodos de pesquisa quantitativa e dos métodos etnográficos para conduzir pesquisas empíricas baseadas em trabalho de campo. Depois de completar sua formação na Alemanha Du Bois voltou para a América para conduzir estudos empíricos sobre os afro-americanos que enfrentaram corajosamente o racismo científico (Morris, 2015) ${ }^{20}$.

Por meio de sua abordagem científica Du Bois desafiou a sociologia de “gabinete/janela de carro". Por exemplo, ele repreendeu o proeminente economista da Cornell University, Walter Willcox ${ }^{21}$, lhe informando da seguinte forma:

A dificuldade fundamental em sua posição é que você está tentando mostrar uma avaliação do problema do negro - somente de dentro do seu gabinete. Isso nunca deve ser feito. Se você pretende continuar escrevendo sobre esse problema, por que não o estuda. Não através de uma janela do carro, mas desça até aqui e realmente faça um estudo em primeira mão (DU BOIS, 1904).

Em contraste, Du Bois frequentemente residiu nas comunidades em que estudou e entrevistou milhares de pessoas. Explicando sua escola de sociologia, Du Bois declarou: "nós estudamos o que os outros discutem". Como resultado da condução de numerosos estudos empíricos, Du Bois inventou uma nova sociologia científica sobre a população afro americana e a desigualdade racial. Essa nova sociologia introduziu uma série de inovações.

\section{TEORIA GERAL}

\footnotetext{
${ }^{20}$ Segundo Aldon Morris (2015) em The Scholar Denied, durante o período em que estudou na Alemanha Du Bois teve aulas e conviveu com Gustav von Schmoller, August Meitzen, Adolf Wagner e Rudolf Gneist. Daí a origem da paixão de Du Bois pela literatura, arte, música alemã, ele era um intelectual alinhado com o pensamento e com a cultura alemã, fundamentais na sua formação intelectual. Esse período é um período de felicidade de Du Bois que é frustrado pelo seu retorno aos Estados Unidos em um contexto marcado pela segregação racial e o racismo, totalmente diferente do contexto alemão do final do século XIX. Segundo Morris (2015, p.17) "Ele [Du Bois] explicou que 'na Alemanha, em 1892, me vi do lado de fora do mundo americano [...] Eles nem sempre pararam para me considerar uma curiosidade ou algo subhumano; Eu era apenas um homem da classe estudantil um tanto privilegiada, com quem eles estavam felizes em conOhecer e conversar'”' (tradução livre).

${ }^{21}$ Walter Francis Willcox (1861-1964) foi um economista, estatístico que durante o período o período que trabalhou na Cornell University esteve associado aos departamentos de História e Ciências Políticas.
} 
Du Bois teorizou que a modernidade era um produto do comércio de africanos escravizados e de séculos de escravidão, pois disponibilizou de uma força de trabalho explorável e mercadorias cruciais - algodão, tabaco, ouro e, açúcar - as quais as burguesias ocidentais utilizaram para desenvolver o capitalismo moderno. Assim, a estratificação racial foi um determinante importante no desenvolvimento do capitalismo, assim como a estratificação de classe social e de status (Morris, 2008).

Du Bois teorizou a linha de cor - ou seja, uma estrutura global durável da supremacia branca sustentada por forças econômicas, políticas e ideológicas semelhantes em todo o mundo - argumentando que ela produzia estratificações raciais que configuraria o mundo social do século XX. As "raças", nessa visão, eram criações sociológicas e não entidades biológicas. Segundo Du Bois, em sua famosa frase preditiva, “o problema do século XX é o problema da linha de cor, a relação das raças mais escuras com as mais claras dos homens na Ásia e na África, na América e nas ilhas do mar" (Du Bois, 1903). Essa marca de sua teorização inspirou predições posteriores, incluindo a observação de Stuart Hall, que apontava que "a capacidade de viver com a diferença é a próxima pergunta do século XXI" (Hall, 1993). Além disso, como destacou Julian Go (2016a), Du Bois foi um dos primeiros cientistas sociais a analisar o colonialismo e como ele foi constitutivo na formação dos impérios ocidentais.

Du Bois (1920) deixa claro que a exploração de pessoas de pele escura nas colônias foi crucial para a aceleração do desenvolvimento industrial do ocidente branco:

Os dias dos muito ricos estão chegando ao fim, na mesma medida em que as nações brancas individuais estão preocupadas com isso. Mas há uma brecha. Há uma chance de exploração em escala imensa para o lucro desmedido, não apenas para os muito ricos, mas para a classe média e para os trabalhadores. Essa chance está colocada na exploração de povos de pele mais escura. É aqui que a mão dourada acena. Não existem sindicatos ou votos, nem questionadores, nem consciências inconvenientes. Esses homens podem ser usados até os ossos, baleados e mutilados em expedições 'punitivas' quando se revoltam. Nessas terras obscuras 'o desenvolvimento industrial' pode repetir de forma exagerada todo horror da história industrial da Europa, da escravidão e estupro a doenças e mutilações, com apenas um teste de sucesso, - dividendos!

Em sua análise das colônias europeias, Du Bois (1920) relacionou raça, violência e capitalismo. Ele argumentou que: 
Colônias, nós chamamos os lugares onde 'negros' são baratos e a terra é rica; são essas regiões remotas onde, como um enxame de gafanhotos famintos, mestres brancos podem se estabelecer para serem servidos como reis, empunhar seus chicotes, estuprar garotas e esposas, crescerem tão ricos como o Rei Creso e enviar para suas casas correntes de ouro. Eles loteiam a terra, esses lugares, mas se aglomeram nos trópicos com essa população não branca: em Hong Kong, em Anam, Borneo e Rodésia, em Serra Leoa, Nigéria, Panamá e Havana - estes lugares são os El Dourados para onde se expandem os poderes mundiais da ganância.

Como teórico Du Bois lançou luz de maneira analítica, distinta e esclarecedora sobre os processos sociais que moldam o desenvolvimento do capitalismo e da modernidade em ampla escala.

Assim como George H. Mead (1934) e Charles Cooley (1902), Du Bois desenvolveu uma teoria do eu/self. O conceito de dupla consciência de Du Bois teorizou como o eu/self é um produto social decorrente da interação e comunicação social ${ }^{22}$. No entanto, esse conceito de Du Bois era teoricamente avançado na época, pois ele demonstrou que, além das influências das interações sociais, simbólicas e da comunicação a autoformação também era moldada pelas relações de raça e poder (Itzigsoh e Brown, 2015).

Du Bois teorizou que as interações entre classe, raça e gênero deveriam ser explicadas para entender a desigualdade social (Morris, 2007). Assim, a ênfase na teoria sobre a classe, raça e gênero antecipou o paradigma da interseccionalidade e a teoria crítica da raça (Morris, 2015).

Por fim, a teorização de Du Bois foi baseada em uma teoria original cujo ponto de vista teórico privilegiava a posicionalidade dos marginalizados e oprimidos (Wright 2002). Sua análise da desigualdade racial decorreu de uma pergunta sobre o povo negro: “como é se sentir como um problema?” (Du Bois, 1903; Go, 2016a).

\section{INOVAÇÕES ESPECÍFICAS A RESPEITO DO ESTUDO SOBRE A POPULAÇÃO AFRO-AMERICANA.}

\footnotetext{
22 A noção de "dupla consciência" em Du Bois refere-se a difícil e conflituosa convivência entre o pertencimento branco e o não-branco, uma vez que o processo de formação subjetiva racializada se dá tendo o polo branco como eixo orientador o negro se vê como tal em função da perspectiva e forma de olhar branca. Trata-se de uma noção que retrata a luta em torno do pertencimento travada no interior do corpo negro.
} 
Du Bois foi o primeiro estudioso a se envolver no estudo científico social crítico sobre a condição social dos Afro-americanos. Entre suas inovações neste campo estão demonstrações que apontam que:

Os afro-americanos eram iguais a outras raças porque era a opressão racial, ao invés das características biológicas, que determinava a posição social dos negros no nível mais baixo da hierarquia racial. (MORRIS, 2015).

'Crime negro' é uma falácia sociológica, pois são as condições sociais e não características raciais que produz o crime. (DU BOIS, 1899).

A comunidade negra, não era uma massa homogênea, como supunha a maioria dos estudiosos brancos era na verdade uma comunidade heterogênea, constituída de classes sociais e experiências diversas (ibid.).

A igreja era uma instituição que serviu como centro organizacional para as atividades sociais e culturais da comunidade negra. É devido aos recursos culturais e políticos alojados em suas igrejas que os negros foram capazes de se libertarem por meio de suas próprias organizações e inteligência coletiva.

Muito antes do movimento moderno dos direitos civis, Du Bois previu que o movimento negro, situado na igreja negra de massa, surgiria para derrubar e combater a desigualdade racial ${ }^{23}$. Portanto, rompendo com a visão comumente aceita, Du Bois previu que os negros se agenciavam por meio das mudanças que ocorriam no curso da história da população negra (ibid.). Du Bois tornou-se um dos primeiros estudiosos a desenvolver uma "sociologia da agência dos oprimidos", elucidando as capacidades de povos subjugados e subalternizados para produzir transformações sociais.

A necessidade de explorar a subjetividade da população negra, argumentando que a opressão racial produzia nos negros a "dupla consciência", que era crucial, tendo em vista sua capacidade, simultaneamente restritiva e possibilitadora, para as perspectivas de libertação negra (Du Bois, 1903).

Assim, Du Bois criou uma nova marca científica de sociologia emancipatória e rigorosa. Duas décadas antes da Escola de Sociologia de Chicago realizar os estudos empíricos rotineiros Du Bois e sua Escola de Atlanta produziram numerosos estudos empíricos usando vários métodos, onde ele foi pioneiro na técnica de triangulação de

\footnotetext{
${ }^{23}$ Para mais informações consultar Aldon Morris, The Origins Of The Civil Rights Movement: Black Communities Organizing For Change. New York : Free Press, 1984.
} 
$\operatorname{dados}^{24}$ (Wright, 2002). Como esses estudos foram realizados em populações rurais e urbanas, Du Bois foi pioneiro na sociologia rural e urbana (Morris, 2015). Enquanto a Escola de Chicago é creditada como a fundadora da sociologia urbana na década de 1920, o livro Philadelphia Negro de Du Bois, de 1899, é uma obra-prima da sociologia urbana, imersa em múltiplas metodologias empíricas (Hunter, 2013). Além disso, Du Bois foi certamente um dos primeiros cientistas sociais a desenvolver análises estruturais da desigualdade social, enquanto estudiosos brancos buscavam avançar em explicações biológicas e naturalistas. Sendo assim, Du Bois emergiu dos seus primeiros estudos científicos como o primeiro a escrutinar números, desenvolvendo surveys, entrevistando, observando participativamente e realizando trabalho de campo sociológico na América (Morris, 2015).

Mesmo assim, os sociólogos brancos ignoraram o pioneirismo de Du Bois. De fato, os sociólogos da Escola de Chicago da década de 1920 se promoveram como os fundadores da sociologia empírica dos estudos raciais. Por conta da marginalização da condição e atividade acadêmica de Du Bois, esse mito sobre as origens da sociologia americana ainda perdura. Em contraste, o sociólogo alemão, Max Weber, estudou os trabalhos de Du Bois e adotou sua opinião de que o problema do século $\mathrm{XX}$ seria o problema global da linha de cor (Morris, 2015). Weber passou a compartilhar a análise de $\mathrm{Du}$ Bois de que a modernidade surgiu tanto da opressão global da raça quanto das distinções de classe e status (Scaff, 2011). Weber, portanto, concluiu que Du Bois era um estudioso com quem nenhum estudioso americano branco poderia se comparar.

Du Bois não criou essa nova sociologia científica sozinho. Acadêmicos e estudiosos esquecidos, até então apagados da história da sociologia, foram cruciais ao desenvolvimento da Escola de Sociologia de Atlanta (Morris, 2015). Os pesquisadores de Du Bois incluíam sociólogos profissionais, estudantes de graduação, pós-graduação, exalunos da Universidade de Atlanta, de outras faculdades, universidades negras e também lideranças comunitárias. Ao investirem em liberação de capital e na construção de redes de intelectuais insurgentes, eles conduziram trabalhos de campo em numerosas comunidades, onde eles eram mais propensos a coletar dados sobre catadores de algodão

\footnotetext{
${ }^{24}$ Por triangulação compreendemos o procedimento metodológico de combinar diferentes técnicas de pesquisa e coleta de dados.
} 
rurais e malandros nas cidades urbanas. Algumas descrições de membros de sua escola ajudam a demonstrar este ponto.

Monroe Work, por exemplo, obteve sua titulação de mestrado em sociologia pela Universidade de Chicago em 1903 e se tornou o primeiro afro-americano a publicar no The American Journal of Sociology, em 1900 tornou-se um prolífico membro da equipe de pesquisa de Du Bois. Ele publicou numerosos e importantes estudos sociológicos. Richard R. Wright Jr., o primeiro afro-americano a obter um doutorado em sociologia na Universidade da Pensilvânia em 1911, também participou nos projetos de pesquisa de Du Bois e publicou estudos sociológicos pioneiros. Edmund Haynes, o primeiro afroamericano a obter um doutorado em sociologia na Universidade de Columbia em 1912, foi co-fundador da National Urban League ${ }^{25}$, tornou-se um membro importante da equipe de Du Bois e publicou vários estudos na área das ciências sociais.

A inventividade de Du Bois, portanto, incluía a capacidade de colaborar com outros pesquisadores talentosos. Assim, ele reuniu uma equipe de acadêmicos, estudantes e líderes comunitários que conduziu pesquisas, apresentando-as em conferências e escreveram artigos acadêmicos elucidando a dinâmica da desigualdade racial. Foi esse quadro de pesquisadores que constituíam a Escola de Sociologia de Atlanta. No entanto, esses estudiosos foram apagados da memória coletiva da disciplina (Morris, 2015).

\section{CIÊNCIA E ATIVISMO}

Um mês antes de Martin Luther King Jr. ser assassinado, ele refletiu sobre as enormes contribuições que Du Bois fez à sociologia e à luta dos negros americanos pela liberdade. Em 1968, King declarou:

Muito antes da sociologia ser uma ciência [Du Bois] foi pioneiro no campo do estudo social da vida da população negra e desenvolveu trabalhos sobre saúde, educação, emprego, condições urbanas e religião. Isso foi em uma época em que a investigação científica sobre a vida dos negros era inacreditavelmente negligenciada e que apenas uma única universidade [Universidade de Atlanta] em todo o país tinha esse programa e foi financiado com US\$ 5.000 por um ano de trabalho (KING, 1968).

\footnotetext{
${ }^{25}$ Anteriormente conhecida como National League on Urban Conditions Among Negroes é importante uma organização negra com sede em Nova York, ela foi fundada em 1910 orientada a ações de promoção de empoderamento econômico, justiça social e direitos civis de comunidades negras. Cf; https://nul.org/mission-and-history acessado em 17/04/20
} 
King reconheceu que o movimento moderno por direitos civis era herdeiro do legado de Du Bois. Enquanto muitos estudiosos permaneciam enclausurados na torre de marfim temendo que o envolvimento político contaminasse a atividade acadêmica, Du Bois não compartilhava essa perspectiva. Para ele, o objetivo principal da ciência era produzir conhecimento válido e útil para as lutas de libertação. Du Bois, junto com ativistas de sua época, desenvolveu o esboço que delineou o movimento moderno dos direitos civis. Du Bois insistiu que a população negra se engajasse e se envolvesse em protestos incessantes para derrubar a supremacia branca. Como resultado, Du Bois pesquisou, estudou, escreveu e marchou para o campo de batalha, liderando importantes movimentos sociais engajados na luta por justiça. Martin Luther King estava ciente de sua dívida com Du Bois: "A história tem ensinado [Du Bois] que não basta que as pessoas se zanguem - a tarefa suprema é organizar e unir as pessoas para que sua raiva se torne em uma força transformadora" (King, 1968).

King lamentava-se não ter tido tempo para se engajar academicamente dadas as demandas e exigências que enfrentava como uma liderança de um movimento político. King admirava a capacidade de Du Bois de se sobressair como estudioso e ativista. De acordo com King, Du Bois “logo percebeu que os estudos não seriam realizados adequadamente, nem as mudanças seriam efetivadas sem o envolvimento em massa dos negros. O estudioso então se tornou um organizador [...]”. King listou os numerosos movimentos de libertação, nacionais e internacionais, em que Du Bois era fundador e/ou participante. King concluiu que Du Bois assustou “imperialistas em todos os países e desconcertou os negros de pensamento moderado nos Estados Unidos que tinham medo desse inquieto, militante, e gênio negro”. De fato, Du Bois organizou movimentos que levam diretamente ao movimento por direitos civis. Em relação a Du Bois, King escreveu que "não seria possível saber onde termina o Du Bois acadêmico e onde começa o Du Bois organizador. As duas qualidades nele eram únicas, e se apresentava como uma força unificadora" (King, 1968). Assim, Du Bois forneceu um novo modelo para estudiosos que desejam entender e mudar o mundo. Ele demonstrou que era possível ser um acadêmico de primeira linha e um ativista prodigioso. Começando com Max Weber, os sociólogos há muito tempo defendem uma postura acadêmica livre de valores, baseado 
na suposição de que a ciência se tornaria tendenciosa quando o estudioso acadêmico não consegue separar seu trabalho cientifico do seu trabalho de ativismo político.

No entanto, estudiosos contemporâneos dedicados ao paradigma da interseccionalidade e à teoria do ponto de vista argumentam de forma persuasiva que é impossível separar ciência e política, porque todo estudo está enraizado em experiências e no lugar social da produção de conhecimento (Go, 2016b; Collins, 2000). Como resultado, há sociólogos pleiteando uma sociologia pública, útil para as lutas de libertação.

Michael Burawoy (2004) liderou este apelo a uma sociologia pública, argumentando que para a sociologia permanecer relevante ela deve retornar a suas origens radicais e fornecer análises críticas que lancem luz nas estruturas de poder e dominação humana. Neste sentido, a alegação de que a atuação acadêmica politicamente engajada perde automaticamente sua objetividade deve ser rejeitada. Por outro lado, as sociologias subalternas buscam ser mais rigorosas que o status quo das ciências, precisamente porque as apostas são muito altas para uma ciência dedicada as questões da transformação social.

Assim, muito antes dos sociólogos exigirem uma rigorosa sociologia pública, Du Bois já estava engajado em uma prática de sociologia pública que era duplamente científica e politicamente engajada.

Du Bois, portanto, há cem anos, forneceu um exemplo desafiador de como estudiosos radicais podem atuar como agentes de transformação social, apesar das vozes clamorosas dos puristas que afirmam que ciência e protesto não se misturam.

\section{DU BOIS E OS MOVIMENTOS SOCIAIS CONTEMPORÂNEOS}

O exemplo de Du Bois é relevante para os movimentos sociais contemporâneos, incluindo o Black Lives Matter. Geralmente os movimentos sociais são impulsionados por jovens, especialmente estudantes. De fato, os movimentos mais bem-sucedidos utilizam jovens por causa de seus horários flexíveis, energia, idealismo e pensamento inovador (McAdam, 1986). Não surpreende que os jovens negros tenham desempenhado papéis cruciais nos movimentos de justiça social da época de Du Bois. É instrutivo indagar sobre como Du Bois respondeu aos jovens manifestantes negros. Ele os aconselhou a seguir as "políticas da respeitabilidade" e proteger suas perspectivas de 
mobilidade e ascensão social? Ou Du Bois aconselhou os alunos a iniciar protestos, atacando a injustiça de cabeça erguida?

A resposta de Du Bois aos protestos estudantis na década de 1920 em sua alma mater $^{26}$, a Universidade de Fisk, fornece um exemplo convincente de sua posição. Na época, o presidente reitor branco da Fisk, Fayette McKenzie, se engajou em uma liderança racialmente tendenciosa ${ }^{27}$. Como resultado, a capacidade dos estudantes e professores de lidar com o racismo da administração da Universidade Fisk foi severamente cerceada. Os estudantes da Fisk foram forçados a seguir as determinações do racismo do Jim Crow. No entanto, esses estudantes quebraram com o protocolo e rebelaram-se. Du Bois apoiou os jovens manifestantes:

E aqui novamente nós estamos, sempre ou potencialmente, dizendo silêncio para as crianças e estudantes, estamos lhes ensinando o subterfúgio e o compromisso, estamos levando-os a fechar as portas por medo de que eles se expressem. E ainda assim, sempre e onde quer que façamos isso, estamos errados, absolutamente e eternamente errados. A menos que estejamos dispostos a instruir nossos filhos a serem covardes, a correr como cães quando eles são chutados, para lamentar e lamber a mão de quem lhes bate no rosto, nós temos que ensiná-los a autorrealização e autoexpressão (DU BOIS, 1924).

Enquanto outras lideranças no interior da comunidade negra repreendiam os protestos estudantis, porque o dinheiro provindo dos brancos para a Universidade Fisk poderia reduzir, Du Bois retumbava que: dignidade e autoexpressão eram aspectos muito mais preciosos do que cestas cheias de dólares da população branca.

Quando Du Bois soube de mais protestos estudantis, ele abraçou a política de agitação:

Novamente, pela segunda vez, e sem conselho nem instigação de fora, os alunos 'se revoltaram' e atacaram. Eles bateram latas, cantaram, eles gritaram e quebraram janelas.

\footnotetext{
${ }^{26}$ É uma expressão do latim que significa "mãe que alimenta" e geralmente é utilizada no intuito de designar as instituições de ensino superior que formaram intelectualmente seus alunos.

${ }^{27}$ Fayette Avery McKenzie (1872-1957) foi um sociólogo especialista e influente na política indigenista do governo que trabalhou com a questão da religião no interior de uma comunidade nativa norte-americana na Reserva Shoshoni em Wyoming, desta pesquisa McKenzie produziu sua tese de doutorado que foi defendida em 1908. McKenzie é conhecido também por ter organizado a Society of American Indians, uma organização nacional dirigida por nativos norte-americanos, fundada em. Durante sua gestão na presidência da Fisk (19151925) McKenzie lidou com inúmeras mobilizações feitas pelo movimento estudantil da universidade e com várias críticas da comunidade negra à sua gestão.
} 
Agradeço a Deus pelo que eles fizeram. Agradeço a Deus que a geração mais jovem de estudantes negros tem coragem de gritar e lutar quando são insultados, zombados e oprimidos [...] Uma rebelião espontânea de almas jovens e feridas, que recusam submeter-se a tirania calculada e sem remorso é uma coisa esplêndida e corajosamente animadora (DU BOIS, 1925).

O Du Bois de Harvard, renomado autor, organizador de povos africanos ${ }^{28}$ e líder da Associação Nacional para o Avanço das Pessoas de Cor (NAACP) permaneceu em solidariedade e consonância com os protestos e movimentos estudantis que protestavam gritando e quebrando janelas. Além disso, Du Bois incentivou o radicalismo por mudanças, pois ele via os manifestantes como, "uma verdadeira radicalidade, o homem que atinge o alto lugar de poder, enquanto o poder [...] apoiado por uma riqueza ilimitada os atinge abertamente e entre os olhos: [os estudantes negros] conversavam cara a cara e não para baixo 'no grande portão'. Deus acelere essa geração” (Du Bois, 1925). Du Bois subsidiou e influenciou diretamente os protestos estudantis:

Em 4 de fevereiro de 1925 mais de cem estudantes ignoraram novamente o toque de recolher e ocuparam o campus da universidade - cantando, gritando, quebrando janelas, revirando assentos da capela ao som de 'Du Bois! Du Bois!' e 'Antes de eu me tornar um escravo, eu serei enterrado no meu túmulo '. (ROGERS, 2012: 40).

Um resultado do apoio de $\mathrm{Du}$ Bois ao protesto dos estudantes foi o fato do presidente branco da Fisk ser forçado a renunciar, permitindo mudanças raciais em sua alma mater.

\section{CONCLUSÕES}

Chegou a hora de faculdades e universidades introduzirem em seus currículos (especialmente na sociologia) o pensamento de $\mathrm{Du}$ Bois. Tendo em vista o que descobrimos sobre Du Bois não incluí-lo nos currículos é praticar racismo acadêmico. Enquanto o livro "Scholar Denied" documenta como Du Bois e sua escola de sociologia

\footnotetext{
${ }^{28}$ Ao se referir ao caráter organizador de Du Bois chamamos atenção para o fato de Du Bois ter participado da organização dos Congressos Pan-Africanos de 1919 1921, 1923, 1927 e 1945 e nesse último foi capaz de articular com lideranças do continente africano como Jomo Kenyatta, Kwame Nkrumah e lideranças da diáspora como George Padmore, Claudia Jones e Amy Garvey os processos que desdobrariam nas lutas de libertação do continente africano.
} 
foi marginalizada e apagada da história da sociologia, há muitas evidências de que tais apagamentos são generalizados. Deegan (1988) demonstrou como sociólogas pioneiras da Hull House têm sido marginalizadas pela sociologia convencional/dominante. Seltzer e Haldar (2015) também documentaram o destino de pesquisadoras da Hull House, incluindo Jane Adams e Florence Kelley, que fizeram contribuições intelectuais fundamentais para a sociologia moderna, mas foram apagadas da memória coletiva da sociologia por causa do sexismo. Esses apagamentos documentam a necessidade de sociologias críticas e reflexivas sempre diligentes, garantindo que todas as contribuições sociológicas sejam consideradas em vez de meramente os dos tradicionais sociólogos de elite.

À luz do tratamento de Du Bois na academia, há várias perguntas que devem ser sondadas.

1. Há vozes importantes em todo o mundo que devem ser incorporadas na academia, mas que são excluídas por causa de discriminação e falta de recursos?

2. Até que ponto as ciências sociais contemporâneas são guiadas por poderosos interesses da elite, fazendo com que cientistas sociais não investiguem desigualdades e realidades que afetam milhões de pessoas?

3. As instituições de elite e prestígio devem ajudar a financiar e subsidiar bolsas de estudos em instituições na periferia da hierarquia de prestígio acadêmico em todo o mundo?

4. O que os acadêmicos podem aprender com as escolas insurgentes nas ciências sociais em outras comunidades oprimidas ao redor do mundo?

Por fim, é hora de desmistificar a ideia de que a sociologia científica americana foi exclusivamente desbravada por um grupo de sociólogos brancos da Universidade de Chicago. Em vez disso, a Escola de Sociologia de Atlanta de Du Bois deve ser reconhecida como uma fundadora crucial e colaboradora inicial da sociologia científica moderna.

Como a perspectiva acadêmica de Du Bois demonstra, a falsa dicotomia que proclama que ciência e ativismo estão em polos opostos deve ser rejeitada. Ao fazê-la a sociologia pode ser restabelecida como um campo de estudo rigoroso que também se destaca na ciência acadêmica e que desencadeia verdades sociais, capacitando a agência 
criativa daqueles que lutam para libertar a humanidade. O legado de Du Bois é um conjunto de ferramentas históricas duradouras e de ideais científicos e ativistas totalmente capazes de orientar as ciências sociais e os esforços para libertar a humanidade.

\section{BIBLIOGRAFIA}

BERNARD, L.L; BERNARD, J. Origins of American Sociology; The Social Science Movement in the United States. New York: Russell and Russell, 1943.

BURAWOY, M. 'Public Sociologies: Contradictions, Dilemmas, and Possibilities', Social Forces 82(4): 1-16, 2004.

COLLINS, P.H. Black Feminist Thought: Knowledge, Consciousness, and the Politics of Empowerment. New York: Routledge, 2000.

COOLEY, C.H. Human Nature and the Social Order. New York: Scribner's, 1902

DEEGAN, M.J. Jane Addams and the Men of the Chicago School, 1892-1918. Transaction Publishers. New Brunswick, NJ: Transaction Books, Inc., 1988

DU BOIS, W.E.B. The Suppression of the African Slave -Trade to the United States of America 1638-1870. New York: Long- mans, Green, 1896.

'The Study of the Negro Problems', Annals of the American Academy of Political and Social Science 11: 1-23, 1898.

The Philadelphia Negro. Millwood, NY: Kraus-Thomson, 1899:1973.

. The Souls of Black Folk. Edited by Henry Louis Gates. Oxford: Oxford University Press, 1903:2007.

'Letter to Walter Willcox' in The Correspondence of W.E.B. DuBois. Vol I. Selections, 1877-1934. Edited by Herbert Aptheker. Amherst: University of Massachusetts Press, pp. 74-75, 1904:1973.

'The Souls of White Folks' in DARKWATER: Voices from within the Veil. New York: Harcourt, Brace and Company, 1920.

.'Diuturni Silent'. W.E.B. Du Bois Papers (MS 312). Special Collections and University Archives, University of Massachusetts Amherst Libraries. 1924.

. 'The Fight at Fisk'. W.E.B. Du Bois Papers (MS 312). Special Collections and University Archives, University of Massachusetts Amherst Libraries, 1925.

. Dusk of Dawn: An Essay Toward an Autobiography of a Race Concept. Edited by Henry Louis Gates. Oxford: Oxford University Press, 1940:2007.

GO, J. Postcolonial Thought and Social Theory. Oxford: Oxford University Press, 2016a.

'The Case for Scholarly Reparations: Race, the History of Sociology, and the Marginalized Man - Lessons from Aldon Morris' Book The Scholar Denied', Berkeley Journal of Sociology, 2016b

HALL, S. 'Culture, Community, Nation', Cultural Studies 7(3): 349-63, 1993.

HUNTER, M.A. 'A Bridge over Troubled Urban Waters: W.E.B. Du Bois's The Philadelphia Negro and the Ecological Conundrum', Du Bois Review 10(I): 1-25, 2013. 
ITZIGSOHN, J; BROWN, K. 'Sociology and the Theory of Double Consciousness: W.E.B Du Bois' Phenomenology of Racialized Subjectivity', Du Bois Review 12(2): 231-48, 2015.

KING, M.L., Jr. 'The Role of the Behavioral Scientist in the Civil Rights Movement', Journal of Social Issues 24(1), 1962.

LEWIS, D.L. W.E.B. Du Bois: Biography of a Race. New York: Henry Holt and Company, 1962.

MADGE, J. The Origins of Scientific Sociology. New York: Free Press of Glencoe, 1962.

MCADAM, D. 'Recruitment to High-Risk Activism: The Case of Freedom Summer', American Journal of Sociology 92(1): 64-90, 1986.

MCKEE, J.B. Sociology and the Race Problem: The Failure of a Perspective. Urbana, IL: University of Illinois Press, 1993.

MEAD, G. Mind, Self and Society. Chicago: University of Chicago Press, 1934.

MORRIS, A. 'Sociology of Race and W. E. B. DuBois: The Path Not Taken', in C. Calhoun (ed.) Sociology in America: A History, Chicago: University of Chicago Press, 503-34, 2007. . The Scholar Denied: W.E.B. Du Bois and the Birth of Modern Sociology. Oakland:

University of California Press, 2015

ROGERS, I.H. The Black Campus Movement: Black Students and the Racial Reconstruction of Higher Education, 1965- 1972. New York: Palgrave Macmillan, 2012.

SCAFF, L.A. 2011 Max Weber in America. Princeton, NJ: Princeton University Press, 2011.

SELTZER, M. and Haldar, M. 'The Other Chicago School - A Sociological Tradition Expropriated and Erased', Nordic Social Work Research 5 (Issue sup. 1: Social Work and Sociology: Historical and Contemporary Perspectives), 2015.

SMALL, A.W. 1916 'Fifty Years of Sociology in the United States (1865-1915)', American Journal of Sociology 21(6): 721-864, 1916.

TURNER, S.P. and Turner, J.H. The Impossible Science: An Institutional Analysis of American Sociology. Beverly Hills, CA: Sage Publications, 1990.

WRIGHT, E. 'Why Black People Tend to Shout!: An Earnest Attempt to Explain the Sociological Negation of the Atlanta Sociological Laboratory Despite its Possible Unpleasantness', Sociological Spectrum 22(3): 325-61, 2002. 